Historic, archived document

Do not assume content reflects current scientific knowledge, policies, or practices. 



\section{An Aerial Survey of Spruce and Fir Volume Killed by the Spruce Budworm in Northern Minnesota}

By Frederick P. Weber, Research Forester

U. S. DEPT. OF AGRICULTURE NATIONAL AGRICI" $\cdots \cdots \times$ LIBRARY Forest Insect Laboratory, Forest Service PR 6 - 1964 U.S. Department of Agriculture Beltsville, Md.

Since the beginning of the current spruce budworm (Choristoneura fumiferana (Clem.)) infestation in northern Minnesota, over three-fourths of a million acres of white spruce (Picea glauca (Moench) Voss) and balsam fir (Abies balsamea (L.) Mill) type have received varying degrees of defoliation. This includes approximately 274,000 acres of severely defoliated stands, characterized by extensive top killing and tree mortality.

Early operation recorder surveys beginning in 1957 showed where the damage was occurring; however, operation recorder surveys provide information only on where the host type is, the degree of defoliation, and the location of dying trees. They do not tell the volume of timber that has been killed. To estimate the volume loss, a new type survey was designed which incorporates both the operation recorder method and a new photomeasurement method supplemented by ground sampling. It was conducted in July 1962, and the results are presented in this note.

\section{METHODS}

$\underline{\text { Operation Recorder Survey }}^{1}$

Figure 1 shows the location of spruce budworm damage to spruce-fir type in northeastern Minnesota, based on operation

${ }^{1}$ For details of making an operation recorder survey, see Heller, R. C., Bean, J. L., and Marsh, J. W. Aerial survey of spruce budworm damage in Maine in 1950. Jour. Forestry 50: 8-11, illus. Jan, 1952. 


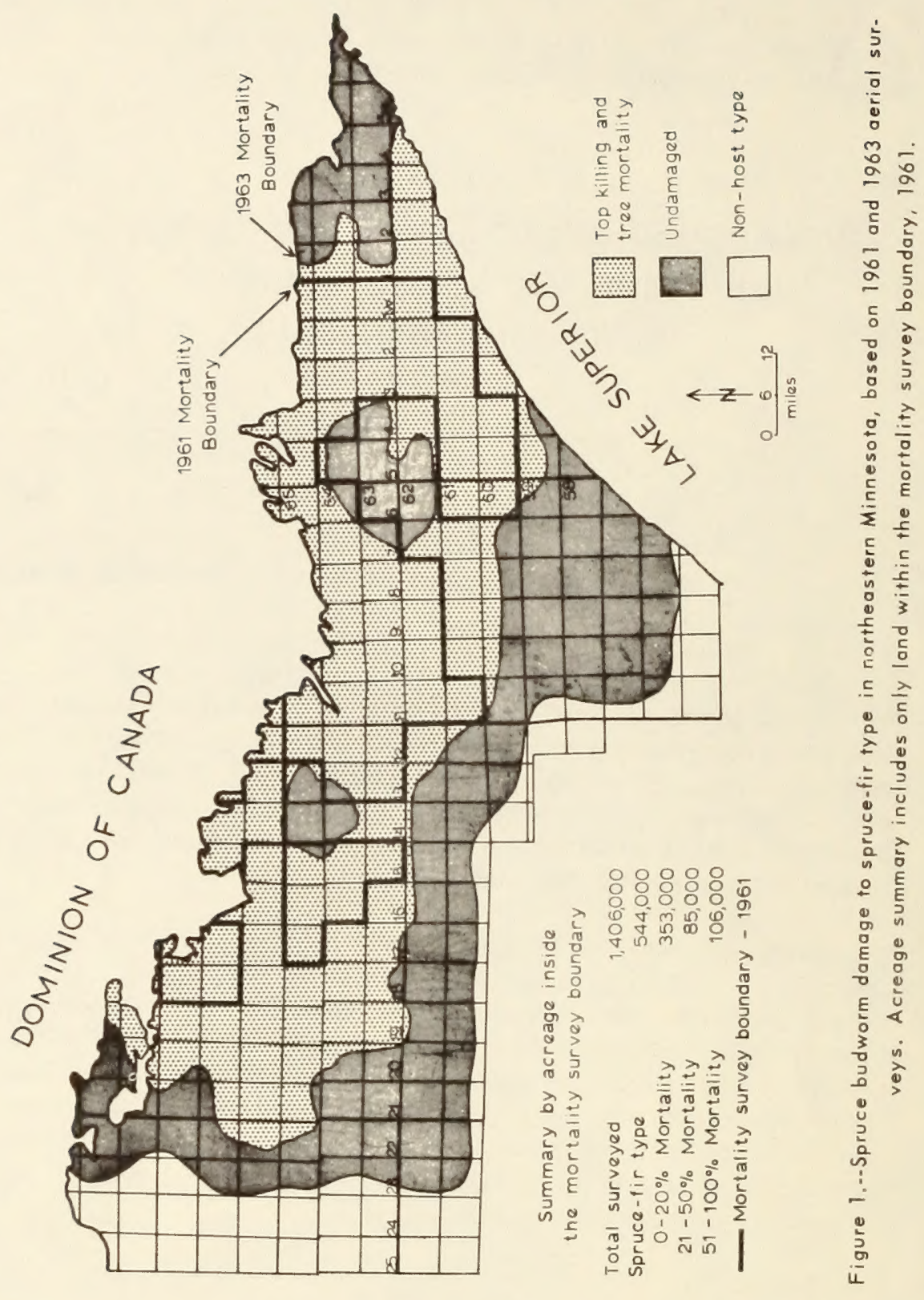


recorder surveys in 1961 and 1963. The area of top killing and tree mortality corresponds to the area of heavy and severe defoliation as defined by the survey. The undamaged area shown corresponds to the area of little or no spruce budworm feeding. Within these two areas, which represent the majority of the commercial balsam fir and white spruce type in Minnesota, other forest types make up roughly three-fourths of the commercial forest land acreage. The flight lines of the 1961 survey were extended beyond the general infestation area to define the host type boundary. The nonhost forest type is shown in white.

The heavy black line in the figure is the 1961 mortality boundary and encloses an area of $1,406,000$ acres. It shows mainly the area of top killing and tree mortality that existed at that time; however, the total infested area was considerably larger. The 1963 operation recorder data, which determined the expanded boundary of top killing and tree mortality, was not used in determining volume loss.

Data obtained from the 1963 operation recorder survey defined the acreages of various forest types within the 1961 mortality boundary. Standing dead spruce and fir were considered stocking for type determinations and were found to cover 544,000 acres. Within this forest type, there were 85,000 acres where mortality of the host species (upland spruce and balsam fir) was 10-50 percent, and 106,000 acres where mortality exceeded 50 percent. This tree mortality occurred in 67 townships within the mortality survey boundary and accounts for a large reduction in acres of living spruce-fir type since the beginning of the infestation.

An additional class of 1963 recorder survey data that was particularly useful in adding to the general knowledge of the infestation area was host type stocking. Within the 1961 mortality boundary, the spruce-fir type was broken into two categories: (1) 255,000 acres, 20-50 percent stocked, and (2) 289,000 acres, over 50 percent stocked.

\section{Aerial Photographic Survey}

Initially, the volume loss survey was limited to a photographic sample of 251 -acre plots within 25 townships randomly selected from the 67 within the mortality survey boundary. Five of the 25 plots were randomly selected for ground sampling in addition to photographic sampling. On these five, the height and d.b.h. of each dead spruce and fir were measured. This type of 
double sampling method was used successfully in the past on similar problems. ${ }^{2}$ The location of each 1 -acre sample plot was determined by locating the lake closest to the center of the selected township that would accommodate seaplane landings and takeoffs. By using a National Forest type map, the spruce-fir stand (1 acre or larger) nearest the lake shore in a clockwise direction from north was selected for the sample.

Later on, data was strengthened with the addition of photographic and ground samples from 24 1-acre permanent study plots located in eight additional townships within the mortality area. For analysis, data from all 49 plots were treated as arising from a random sample.

All 49 study plots were photographed in July 1962 with a Hulcher $^{3} 70-\mathrm{mm}$. aerial camera using Super Anscochrome ${ }^{3}$ ASA 125 color film at a scale of $1: 1584$ ( 2 chains per inch). A Cessna ${ }^{3}$ 195 equipped with floats was used for the aerial platform.

Two photomeasurements were used to arrive at volume estimates of mortality in spruce-fir stands: (1) average stand height, measured with a parallax bar to the nearest foot, and (2) crown closure percent of dead host species, calculated from a dot template having 144 dots per square inch. A detailed report of the photomethods used is being prepared and will include the development of prediction equations and resulting cubic foot aerial volume tables used in this study.

Three experienced photo-interpreters at Beltsville were assigned to make the photomeasurements. The variations in measurements among them were so small that one interpreter would be adequate to make similar measurements in the future.

\section{RESULTS AND DISCUSSION}

The mean volume mortality estimate from the 49 plots was $221 \pm 55$ cubic feet per acre, as derived from the regression based

${ }^{2}$ Heller, R. C., and Schmiege, D. C. Aerial survey techniques for the spruce budworm in the Lake States. Jour. Forestry 60: 525-532, illus. Aug, 1962.

Aldrich, R. C. A study to determine the possibilities of aerial color photography for. following the trend of an insect outbreak, 1962. (Unpublished progress report on file at Beltsville Forest Insect Laboratory, U.S. Forest Serv., Beltsville, Md.)

${ }^{3}$ The mention of commercial products does not imply endorsement by the U.S. Department of Agriculture, Forest Service.

${ }^{4}$ Heller, R. C., Aldrich, R. C., and Bailey, W. F. Evaluation of several camera systems for sampling forest insect damage at low altitudes. Photogrammetric Engin, 25: 137-144, illus. March 1959. 
on ground vs. photosampling. This estimate applies to the 1961 mortality area and includes samples in lightly killed stands as well as in stands where complete mortality occurred. Since the error term was computed for one standard deviation, it is expected that this interval will include the true mean two times out of three.

Applying the above volume loss per acre over the 544,000 acres of host type within the 1961 mortality boundary gives a total volume estimate of $120,224,000 \pm 29,920,000$ cubic feet, or approximately 1.5 million cords of dead balsam fir and white spruce. This estimate of the volume loss for the spruce-fir type is within a 25 percent error, which is considered acceptable for this type of survey. However, studies will be continued in 1964 in an effort to improve upon sampling designs and to strengthen mortality estimates.

The estimated losses to date represent a 30 percent reduction in spruce-fir volume since the inception of the outbreak, and tree mortality will continue for some time after the epidemic subsides. The dead timber still standing will be a fire hazard for many years.

The sample photography technique for arriving at volume estimates of mortality resulting from insect damage is timesaving and much less expensive than present ground methods. Quite probably, the same technique could be employed to estimate the volume of dead trees in other problem areas. 


